Development of Some Mechanical Inventions". His address, he said, followed a well-beaten track, but as many uncritical accounts and inaccurate illustrations have been published regarding the early history of pumps and engines, he thought it would be of interest to consider some of the earliest printed records. Recent research has shown that much less is known of such men as Ctesibius and Heron than our fathers thought they knew ; and even in the case of Heron, the earliest manuscripts are posthumous to the extent of more than a thousand years. The first printed edition of his "Spiritalia" was in Latin and was published at Urbino in 1573. In this is described the first known application of heat to produce motion in fluids, a device for opening temple doors by the agency of heat, and the famous æolipyle. The word 'æolipyle' has been used by writers in three senses, namely, (1) for a vessel shaped like a retort for producing a jet of steam, (2) for Heron's engine and (3) for a wheel impelled by steam as invented by Branca. The word means the doorway of Eolus, that is, that of the cave in which the winds were kept. After touching upon some of the inventions described by Agricola, Porta, de Caus, Branca, D'Acres, von Guericke, Boyle and the Marquis of Worcester, Mr. Dendy Marshall made some interesting remarks on Papin and his invention of the safety valve. To the plug valve, Papin added the lever and moveable weight, but he did not propose it as a safety valve or hint that it might be useful to prevent explosions. From Papin, Mr. Dendy Marshall turned to the work of Savery and Newcomen on the steam engine, and concluded with some remarks on the early history of tramways, railroads and mechanically propelled vehicles.

\section{Road Traffic in the United States}

IN a recent radio talk given over the Columbia Broadcasting System, Prof. S. S. Steinberg, of Maryland University, discussed the highways of the United States. With more than 25 million motor vehicles, the business of highway transportation is one of the largest in the country. Last year, holiday motorists in the United States spent almost 600 million pounds. Highway facilities are still far from complete; only five per cent of the three million miles of rural roads are hard-surfaced, while only thirty per cent have received any kind of improvement. In many places, need for reconstruction is urgent, and the mileage of secondary light traffic roads required is very great. The loss of life due to accidents is high, as almost a hundred persons are killed every twenty-four hours, and last year one out of every hundred of the population was injured in a road accident, one of the gravest risks being the 'railroad grade' crossings, of which there are 240,000. About 1,500 persons are killed annually at these crossings; at least 30,000 such crossings are dangerous, and it will take many years before they can be made safe. Congress has provided sixty million pounds of emergency relief funds for this purpose, and the development of 'farm to market' roads will bo a great boon to the country. The work will provide employment for many at present unemployed as the cost of constructing roads is mainly for labour. $\mathrm{Mr}$. Robinson points out that the highways affect everyone vitally as they are the arteries which carry the life-blood of agriculture, commerce and industry, as well as bringing many social and educational amenities.

\section{London and Home Counties Joint Electricity Authority}

UNDER the Electricity Acts of 1919 and 1922, joint electricity authorities were set up, which were to be representative in these districts of the authorised undertakers, the local authorities, the county councils, the large consumers and other interests. In a pamphlet describing the opening of new electricity showrooms in Sutton, a list of those composing the Joint Electricity Authorities for London and the home counties is given, and a record of the progress that has been made since the Authority took over the undertaking. The list of the members is thoroughly representative, and wonderful progress has been made in developing the industry. By instituting two-part tariffs, assisted wiring and hire and hire-purchase schemes, the electric supply has been made available to the poorest people in the district served, which is mainly residential. The supply area covers 190 square miles and is divided into an inner and outer zone, consumers in the latter having to pay slightly more. The work was taken over in July 1932, and in July 1935 the number of consumers had increased by 89 per cent, the load having more than trebled. The Authority has done much useful work in standardising the apparatus and systems it has inherited. The whole of Surbiton has been changed from direct current to alternating current, and in Sutton the supply is being converted from 200 volts to the standard 230 volts. Practically the whole of the supply is being received in bulk from the Central Electricity Board. The bulk supply from the Grid is taken at $\mathbf{3 3}$ kilovolts, transformed at the Grid substations to 11 kilovolts and then transmitted to the Authority.

\section{Climate and Health}

Ar the Harrogate Congress of the Royal Institute of Public Health, Mr. L. C. W. Bonacina delivered an address on "The Study of Weather and Climate in Relation to Public Welfare", which has been published in the Journal of State Medicine (43, No. 10). $\mathrm{He}$ points out that the effect of climate on general well-being is so complex that it is not possible to discriminate between the different elements, but that in Great Britain the general effect is distinctly favourable. Hence it follows that the effect of a marked change of climate, even if superficially an improve. ment, as for example a doubling of the amount of bright sunshine, might not really be to our advantage. The great importance laid on sunshine is "probably only an exaggerated response to the evil consequence of smoke-vitiated light and air in the great industrial centres, and the curative results in proper doses of natural or artificial sunlight". The wind and the rain, by cleansing the air, are also of great value, 
and Mr. Bonacina is in full agreement with the trend of modern ideas in emphasising the importance for health of frequent contrasts of weather, and especially of temperature and wind. $\mathrm{He}$ ends on a practical note by insisting that the open-air study of weather and especially clouds also makes for health by training the powers of observation and inference. Forecasts 'on tap' by wireless are a very good thing, but there are occasions, for example in mountaineering, when much discomfort or even risk might be avoided by the ability to foresee a storm an hour or two ahead.

\section{Meteorology of Southern Rhodesia}

THE annual report of the Meteorological Department of the Department of Agriculture of Southern Rhodesia for the year ended June 30, 1934, follows the general lines of previous reports (Salisbury: Department of Agriculture, 1934). In the rainy season of 1933-34, as in that of the preceding season, there was substantially less rain than usual, although the formula used for predicting the season's fall had indicated an excess of rain. During the five years for which this computation has been made, this was the first occasion on which the sign of the departure from the normal was not correctly given by the formula. An Aircraft Weather Service that had been organised for Imperial Airways operated satisfactorily during this year, and it was decided to extend the service to all aircraft. Arrangements were made to transfer the observatories at Salisbury and Bulawayo to the aerodromes, where they will be maintained by a staff of two, who will prepare regular weather reports and forecasts, and make observations of the upper winds. According to the report, the provision of an adequate weather service for aircraft is now regarded as the most important function of the Meteorological Department. The number of tables in the report has been reduced owing to financial stringency; but among those included is an interesting one showing the average $R$ hodesian rainfall for thirtysix years. In the first season, 1898-99, the fall was based on the records of seven rain-gauges, and in the most recent (1933-34), on three hundred and fortyfour.

\section{A Totalising Anemometer}

IN the Hydrographic Review, 12, No. 1, Dr. J. N. Carruthers describes a suggested totalising anemometer for oceanographers, the records of which he considers likely to be of value in climatology. Although the ordinary Robinson anemometer is a totalising instrument in so far as it registers the number of miles and fractions of a mile of air that have flowed past the anemometer in a given time, it does not distinguish between the different, wind directions, and its records can only be used for obtaining the total run in particular directions in the case of the more complicated self-registering form of this instrument that records automatically both the run and the direction, and then only after laborious calculations. In the instrument described by Dr. Carruthers, a wind vane is used which rotates a vertical rod bearing at its lower end a circular tank divided radially into eight equal compartments, each of which has a draw-off tap. A separate mast carries a 4-cup anemometer which makes and breaks an electric circuit after a certain run of wind past the cups. When the circuit is made, it energises a solenoid and the latter rocks a small pipe which is pivoted on the rim of a tank in which water is maintained at a constant level by means of an ordinary ball valve. This pipe carries a dipper which delivers a definite quantity of water through it into whichever of the eight compartments of the circular tank is beneath at the time. At the end of a period of observation, the total run of air in each of the eight directions is readily obtained by drawing off and measuring the quantity of water in each compartment.

\section{Co-ordination of Scientific Surveys}

Aт the recent meeting at Norwich of the British Association, Mr. E. Wyllie Fenton made an interesting plea, in a paper read before Section $\mathrm{K}$ (Botany), for the extension and co-ordination of the existing Ordnance and Geological Surveys into a wide body to carry out periodic surveys not only of topography, rocks and soils but also of vegetation, agriculture and animal life. Mr. Wyllie Fenton's illustrations of the wider need were mainly botanical, as for example, the invasion of valuable land in Scotland by bracken moving downhill to the better land "like a series of plant glaciers", and the association of this fact with changes in land settlement and agricultural practice. A plea was advanced for a prompter recognition of these significant changes in vegetation and in the results of changes in population. distribution, etc., with the argument that a more scientific utilisation of the land, in housing development, in agriculture and in forestry, etc., would be possible if such a general scientific survey service provided the data. Mr. Fenton recognises, however, the ambitious nature of such a proposal, and suggests that a start might be made by the attachment of a few botanists to the Geological Survey.

\section{Metals in the Chemical Industry}

IN his Jubilee Memorial Lecture of the Society of Chemical Industry delivered before the Yorkshire Section at Leeds on November 6, Dr. C. H. Desch took as his subject "Metals in the Chemical Industry". The range of both ferrous and non-ferrous metals available for the purposes of chemical industry has been immensely widened in recent years. Resistance to chemical attack is one of the first considerations, and as no one material is resistant to all chemical agents, a choice must be made in each instance, for which ample data now exist. Corrosion fatigue, caused by the simultaneous action of fluctuating stress and of a chemical agent, is quite different from the sum of the actions of fatigue and corrosion, and is responsible for many unexpected failures. Special conditions arise where high temperatures and pressures are involved. Resistance to 'creep' is required as well as chemical resistance, and internal changes may cause progressive weakening. Not only chemical 